Sociohistórica

ISSN: 1852-1606

publicaciones@fahce.unlp.edu.ar

Universidad Nacional de La Plata

Argentina

\title{
Estado y ciencia empresarial en la Argentina del agronegocio. Implicancias políticas del conocimiento ¿útil?, un estudio de caso
}

Gárgano, Cecilia

Estado y ciencia empresarial en la Argentina del agronegocio. Implicancias políticas del conocimiento ¿útil?, un estudio de caso

Sociohistórica, núm. 46, 2020

Universidad Nacional de La Plata, Argentina

DOI: https://doi.org/10.24215/18521606e107

Atribución no comercial compartir igual (CC BY-NC-SA) 4.0 


\title{
Estado y ciencia empresarial en la Argentina del agronegocio. Implicancias políticas del conocimiento ęútil?, un estudio de caso
}

State and business science in Argentina's agribusiness.Political implications of ¿useful? knowledge, a case study

Cecilia Gárgano

DOI: https://doi.org/10.24215/18521606e107

CONICET-Universidad Nacional de General San Martín

- Universidad de Buenos Aires, Argentina

garganocecilia@gmail.com

Recepción: 10 Abril 2019

Aprobación: 30 Septiembre 2019

Recepción: 10 Abril 2019

Aprobación: 30 Septiembre 2019

\section{Resumen:}

El artículo indaga uno de los principales ámbitos dedicados a la investigación en tecnología agropecuaria y producción agrícola en Argentina: la Estación Experimental Agronómica Obispo Colombres (EEAOC). Con el objetivo de analizar dinámicas de producción y apropiación de conocimientos y transformaciones en las relaciones entre Estado, científicos y empresas, se reconstruye la trayectoria de esta institución centenaria y se estudia una de sus agendas de investigación orientada a la obtención de una variedad nacional de soja transgénica. Mediante fuentes escritas y entrevistas realizadas a científicos y técnicos, se analizan concepciones vigentes sobre el conocimiento producido en esta agencia estatal y sus vinculaciones con transformaciones socioeconómicas del espacio rural. Las conclusiones señalan como principal resultado la identificación de un tipo de ciencia de carácter empresarial, fuertemente articulada al esquema productivo del agronegocio, en la que opera una alianza entre saberes expertos y no expertos mediada y garantizada por el Estado.

Palabras Clave: Ciencia empresarial, Conocimiento, Estado, Agro, Soja transgénica.

\begin{abstract}
:
This article explores one of the main institutions dedicated to agricultural technology research and agricultural production in Argentina: the Obispo Colombres Agronomic Experimental Station. With the aim of analyzing production dynamics and knowledge appropriations and transformations concerning the State, scientists and companies, this work reconstructs the trajectory of this century-old institution and studies one of its research agendas: the search for a national variety of transgenic soybeans. Through written sources and interviews with scientists and technicians, current conceptions about the production of knowledge in this state agency and its links with socio-economic transformations of rural space are analyzed. The main conclusion of this article is the identification of an entrepreneurial science, strongly articulated to agribusiness productive schemes, in which an alliance between expert and non-expert knowledge operates mediated and guaranteed by the State.
\end{abstract}

KEYwORDS: Commodity, Centered science, Knowledge, State, Agro, Transgenic soybeans.

\section{INTRODUCCIÓN}

¿De qué forma se construyeron definiciones a lo largo de la historia contemporánea en torno a la utilidad del conocimiento científico y tecnológico? ¿Qué continuidades y qué rupturas experimentaron en este tránsito las prácticas y los discursos de sus protagonistas? Estos dos amplios interrogantes se encuentran en la base de este texto y de una investigación mayor que lo origina, que analiza en perspectiva histórica procesos de producción y apropiación de saberes científicos y tecnológicos generados en ámbitos estatales y orientados al espacio rural argentino, un sector que históricamente ha signado los destinos políticos y económicos del país. Un tercer interrogante transversal se ubica en el presente:ęen qué medida estas trayectorias, de espacios de investigación y saberes, aportan elementos para analizar caracterizaciones vigentes sobre la orientación de la ciencia y la tecnología? 
Este artículo aborda la trayectoria de una de las principales agencias estatales dedicada a la investigación en tecnología agropecuaria y producción agrícola: la Estación Experimental Agronómica Obispo Colombres (EEAOC). El objetivo general es analizar dinámicas de producción y apropiación de conocimientos, modos de institucionalización de las prácticas científicas, y relaciones entre Estado, científicos y empresas. En particular, el texto busca problematizar concepciones vigentes sobre el funcionamiento de la EEAOC, a partir de discursos de algunos de sus integrantes y funcionarios del sector, y su vinculación con: i) su propia trayectoria; ii) sus agendas de investigación, específicamente en torno a la obtención de una variedadestatalde soja transgénica; iii) las transformaciones políticas y socio-económicas del espacio rural.

La elección del caso responde a dos razones clave. En primer lugar, se trata de una institución pionera, creada en 1909 en la provincia de Tucumán, por lo que su trayectoria atraviesa buena parte de la historia argentina. En segundo lugar, actualmente es señalada por decisores políticos del área de Ciencia y Técnica como modelo exitoso de referencia en materia de políticas de vinculación tecnológica y desarrollo científico. En este sentido, indagamos qué parámetros son los que operan en esta caracterización, en qué medida es producto de una construcción histórica asociada a trasformaciones socio-económicas y disputas, cuáles son las autopercepciones de algunos de sus científicos y técnicos sobre sus propias prácticas, y cómo se vinculan con la trayectoria de la Estación Experimental. Al mismo tiempo, interesa a los fines de este trabajo poner en diálogo el caso estudiado con algunos aportes provenientes del campo de los estudios sociales de la ciencia y la tecnología, la historia y la filosofía de la ciencia, que han problematizado la relación entre ciencia, tecnología y sociedad.

La hipótesis de este artículo es que a lo largo del siglo XX fueron generándose una serie de validaciones del accionar de la EEAOC que configuraron una noción hegemónica de la utilidad del conocimiento allí producido, a partir de una alianza entre saberes expertos y no expertos (y sujetos colectivos e individuales que los encarnaron) en la que el Estado ocupó (y ocupa) un rol destacado, alianza que terminó consolidando una ciencia empresarial articulada al proceso local de acumulación. Estudiamos el proceso de gestación y desarrollo de esta alianza, mediante el análisis de diversos materiales documentales (prensa gráfica, documentos institucionales, fuentes secundarias especializadas) y discursos de científicos y técnicos relevados durante un trabajo de campo realizado en la Estación Experimental. ${ }^{1}$

El primer apartado retoma algunos de los estudios que analizan vinculaciones entre la ciencia y la tecnología, en particular en torno a la noción de "tecnociencia”, y plantea interrogantes en función del caso analizado. El segundo narra sintéticamente la historia de la EEAOC, recuperando algunas transformaciones y continuidades en su trayectoria. El tercero analiza una de sus agendas de investigación recientes: la obtención de Munasqa RR, una variedad estatal de soja transgénica. El cuarto explora discursos de algunos de los integrantes de la institución y de funcionarios del área, analizando autopercepciones de las prácticas científicas y el rol que ocupa la conceptualización de un conocimiento útil en ellas. Finalmente, en las conclusiones se recuperan los aportes alcanzados y se enuncian nuevas dimensiones de investigación.

\section{Ciencia, tecnología Y tecnociencia: Debates conceptules Y PReguntas de INVESTIGACIÓN}

Tomando como hito la Segunda Guerra Mundial, y en particular el Proyecto Manhattan, una gran cantidad de autores identifican en este momento de la historia el comienzo de una nueva relación entre la ciencia y la tecnología. ${ }^{2}$ La transformación de las prácticas científicas, ligada a la imbricación entre ciencia y tecnología y al rol definitorio de ambas en cuestiones de Estado, ha llevado a generar un consenso sobre el origen en este período de la "tecnociencia" (Latour, 1983; Echeverría, 2003; Linares, 2008; Gibbons et al., 1994; Nowtony, Gibbons y Scott, 2001, entre otros). De la mano de las políticas científicas, el avance tecnológico se convirtió en la clave del poder económico y militar, y a la vez la ciencia se transformó en la llave del cambio tecnológico (Dickson, 1988). La tesis de Gibbons y otros postuló la existencia de dos modelos de 
producción de saberes: un modo 1 clásico, vigente desde la revolución científica a la Segunda Guerra, y un modo 2 contemporáneo, en el que las ciencias reconfiguraron sus prácticas, instituciones, epistemologías y su relación con el mundo. Así, el modo clásico estaría concentrado en el ámbito de las Universidades, siendo institucionalmente estable, con identidades profesionales claras asociadas a enfoques disciplinares, una validación del saber dada por la evaluación de pares y un financiamiento predominantemente estatal (Gibbons et al., 1994). Por el contrario, el modo 2 estaría asentado en un espacio más amplio que incluye Universidades, empresas y laboratorios mixtos, siendo un régimen más flexible y transitorio asociado a enfoques transdisciplinares, con una evaluación construida en función de quién demande el conocimiento producido (gobiernos, empresas, etc.), y un financiamiento mayoritariamente privado. Una "tecnociencia" cuya agenda y temporalidad están definidas por exigencias sociales, políticas y empresariales (Gibbons et al., 1994). Esta concepción se vincula al planteo de Echeverría (2003), quien señala que la tecnociencia implica una ruptura en la dimensión axiológica de la ciencia. Por su parte, según Linares (2008) se presentan trasformaciones en las racionalidades implicadas. Mientras que hasta el advenimiento de la tecnociencia primaría una racionalidad de tipo logocéntrica, a partir de ella lo hace una de carácter pragmático-utilitario (Linares, 2008). Pestre (2005), en cambio, se opone a la tesis de Gibbons et al. (1994) y Nowtonyet al. (2001). Si bien coincide en identificar cambios profundos en el modo de concebir y practicar la investigación científica, discrepa con las caracterizaciones y periodizaciones presentadas por estos autores. Así, afirma que ambos "modos" han coexistido desde el Renacimiento y señala tres puntos nodales, que retomaremos a la luz de nuestro estudio de caso.

Por un lado, afirma que el "modo 1" no existió jamás en forma pura ya que: "La ciencia moderna como institución, la que se organiza en los siglos XVI y XVII, fue siempre del más alto interés para los poderes políticos, económicos y militares" (Pestre, 2005: 26). Con esto alude a que estos saberes tempranamente ofrecieron técnicas, armas, ideas, normas; es decir, dominio práctico del mundo. En otras palabras, ciencia y poderse encuentran imbricados desde los comienzos de la ciencia moderna. En segundo lugar, explicita que, antes que un reflejo de la práctica científica previa a la Segunda Guerra, el discurso de la "ciencia pura" es un discurso del siglo XIX, construido en instituciones académicas por los propios científicos. El mismo que contribuyó a legitimarlos y construirlos como desinteresados en un momento en que, precisamente, su inserción en la industria cobraba nueva forma y a configurarlos como políticamente neutros: no podrían ser considerados responsables de los malos usos que se hicieran de sus descubrimientos (Pestre, 2005: 29). En tercer y último lugar, indica que este relato de la ciencia pura aún impera en los discursos sobre la ciencia y entre los propios científicos, cumpliendo una función ideológica. La de sostener y reactivar la escisión entre objeto y sujeto que conoce el mundo, y la división entre prácticas cotidianas ordinarias (aun las de la propia práctica científica, como los trabajos de campo, las campañas o los ensayos) y los "informes purificados" o los papers en los que los hechos se enuncian como separados de todo sistema de valores y en consecuencia como socialmente neutros. "Se vuelven así indiscutibles, principalmente para los profanos" (Pestre, 2005: 29). De este modo, este discurso aparece con un objetivo claro: "ayudar a olvidar lo que nos define, a olvidar la naturaleza profundamente local y social de nuestros saberes, a olvidar que todo proceso de producción de conocimientos se halla siempre ya situado" (Pestre, 2005: 29). En este planteo, el universo de los saberes que acompañan la configuración de la ciencia moderna, que no casualmente es el de la transición al capitalismo, no es la contemplación ni la creación de saberes "puros" sino el de la "eficacia magnetizable y pragmáticamente concebida" (Pestre, 2005: 31). Modos de hacer instrumentales colonizan y transforman los modos de concebir, mientras se formalizan y traducen saberes artesanales y populares. Un nuevo despliegue de conocimientos, en consonancia con una redefinición del orden social.

Este autor también identifica en un período de larga duración, entre 1870-1970, una imbricación entre tecnociencia, industria y Estados-nación (Pestre, 2005). En este punto cabe recordar el análisis pionero de la ciencia y la tecnología realizado por Marx, quien también señaló este mismo período, el de la Gran Industria de fines del siglo XIX, como el momento en que ciencia y tecnología comienzan a imbricarse y pasan a operar 
en forma subordinada a la lógica del capital (Marx, [1867] 2003). Finalmente, en línea con lo señalado por otros analistas (Krimsky, 1991; Palladino, 2002, entre otros), Pestre (2005) encuentra un tercer quiebre histórico a partir de la década de 1970, al que identifica como el comienzo de un nuevo régimen de producción de saberes. Dos elementos lo distinguen: un notable y cualitativo incremento de la mercantilización del conocimiento producido y una modificación en la percepción social de la tecnociencia, que cuestiona su carácter benefactor y desconfía de sus potenciales riesgos (Pestre, 2005). ${ }^{3}$

A partir de este análisis realizado por Pestre (2005), quien al igual que otros autores mencionados se refiere a la producción de conocimiento en países occidentales centrales, nos interesa analizar algunas de sus consideraciones a la luz del estudio de la producción local de conocimiento. En particular, repararemos en su observación de un largo tránsito histórico respecto de cómo el mundo del conocimiento estuvo mezclado tempranamente con el de la producción, y cómo la eficacia práctica ocupó el centro de las preocupaciones (Pestre, 2005: 37). ¿Implica esto concebir un continuum sin fisuras hasta el presente? En absoluto. Más bien, se trata de identificar la naturaleza de las trasformaciones. En función del estudio de la trayectoria de la EEAOC, nos interesa indagar: ¿cuál fue la construcción histórica de la noción de "utilidad" del conocimiento científico y tecnológico allí producido? ¿Qué discursos acompañaron y sostienen su validación? ¿Qué vinculaciones entre las dimensiones políticas, económicas y epistémicas operaron? Y, en definitiva, ¿para qué y para quiénes es producida esa (tecno)ciencia?

\section{Breve historia de LA EEAOC}

La EEAOC es una de las primeras instituciones dedicadas a la investigación y desarrollo de tecnología agropecuaria de Argentina. Su creación en 1909 estuvo precedida por la transformación del Departamento Nacional de Agricultura en Ministerio, en 1899, situación que a su vez fue acompañada por la promoción de planes de extensión rural y la creación de numerosas estaciones agrícolas, granjas experimentales y escuelas agronómicas a nivel nacional (Djenderedjian, 2014; Graciano 1988). ${ }^{4}$ Se distinguió desde sus inicios por implementar un esquema organizativo que aún orienta sus planes de trabajo y su financiamiento. Si bien se trata de una institución estatal, autárquica y dependiente del gobierno provincial, su directorio está compuesto por representantes del sector agroindustrial, empresarios de los principales rubros de la producción agrícola tucumana. Y su financiamiento depende de una tasa fijada por ley para las diversas producciones agrícolas y agro-industriales, que están gravadas con un porcentaje que se destina a la Estación Experimental. El impulsor del proyecto de creación y primer presidente de la EEAOC, Alfredo Guzmán, por entonces era senador provincial y dueño de un ingenio azucarero. En diversas estadías en el exterior había observado que los ingenios tenían su propio departamento de investigación, y con ese espíritu propuso que en lugar de que cada ingenio desarrollara el propio, existiera uno común que investigara para dar soluciones a sus problemas. Según caracteriza el actual director de la Estación Experimental, Guzmán

tuvo la visión de proponer, a diferencia de otras en el mundo, una institución oficial, porque eso le da una serie de ventajas, pero financiada por el sector privado. Un modelo de una institución pública, financiada por el sector privado, dirigida por el sector privado. Ese modelo es el modelo que sigue vigente hoy, 106 años después (Ploper, 2016, entrevista).

Este modelo organizativo, de institución pública en buena medida financiada y "dirigida por" el sector privado, originalmente se plasmó en una Junta Asesora, integrada por tres de los principales plantadores de caña de azúcar de la provincia. Actualmente, el Directorio es designado por el Poder Ejecutivo provincial, que usualmente "les pide nombres a las cámaras gremiales de cada uno de los sectores. A la Sociedad Rural, a la Asociación Tucumana del Citrus, etc." (Ploper, 2016, entrevista). A su vez, estos representantes eligen anualmente al presidente y al vicepresidente. Este esquema lleva a muchos de los integrantes de la EEAOC a enfatizar que es una institución que desde sus inicios está directamente conectada a las "necesidades del sector". De este modo, el lema institucional rescata que la prioridad es "encontrar soluciones" y el perfil 
buscado para los investigadores no es el de publicadores seriales de papers, sino el de aquellos que pueden articular la investigación a necesidades productivas. ¿Cuáles fueron, entonces, y cómo son concebidas las necesidades a las que deben abocarse la investigación científica y el desarrollo tecnológico en una institución que es tomada como referente dentro del complejo científico-tecnológico nacional? ¿Cómo se ha construido históricamente la noción de "conocimiento útil"?

Empresario azucarero de activa participación política en el gobierno de la provincia, Guzmán presidió la EEAOC entre 1909 y 1917, y entre 1930 y 1931. En estas primeras etapas fue fundamental la contratación de técnicos extranjeros, ya que aún no existía una masa crítica de investigadores locales que más adelante nutriría el plantel de la institución. Como parte de este proceso, en tiempos en los que en Europa se vivía la Primera Guerra, William Ernest Cross, un químico de origen inglés, llegó a Tucumán. Permaneció treinta y dos años dirigiendo las investigaciones científicas. A partir de la década de 1920 comenzó a producirse una paulatina incorporación de profesionales tucumanos. En 1946, siguiendo la recomendación de la Cámara de Diputados, el gobierno provincial dictaminó la intervención de la EEAOC. Un año antes había asumido la presidencia de la nación el general Juan Domingo Perón. Si la primera etapa de la EEAOC estuvo marcada por la impronta de los técnicos extranjeros, la que se inauguró en 1946 tuvo protagonismo de técnicos formados en el país, que condujeron las investigaciones. La intervención iniciada en 1946 fue dictaminada por decreto provincial y el personal de campo de la institución la apoyó con una huelga obrera. El contrato de Cross no fue renovado, y se suspendió el accionar del Directorio. Mientras tanto, en un marco de crisis económica, el segundo Plan Quinquenal evidenciaba el fin de cualquier atisbo de reforma agraria, y las políticas se centraban en el incremento de la productividad agrícola. Tiempo después, en 1955 el golpe de Estado autodenominado "Revolución libertadora" puso fin al segundo gobierno de Perón. Comenzó entonces una nueva intervención federal de la EEAOC, presentada como una etapa de "normalización", que continuaría hasta 1959, y representantes de los capitales agroindustriales se reincorporaron con voz y voto. ${ }^{5}$

En simultáneo, en 1956 se produjo la creación del Instituto Nacional de Tecnología Agropecuaria (INTA), de alcance en todo el territorio nacional. Su puesta en marcha era parte de un proceso regional, heredero de la revolución verde. Impulsada por Estados Unidos primero en México y luego exportada al resto del mundo, ésta transformó las pautas de producción y consumo del espacio rural. El nuevo paquete tecnológico, basado en el uso combinado de semillas modificadas genéticamente (híbridas), insumos (herbicidas y pesticidas) y nuevas prácticas de manejo, incrementó tanto los rendimientos como la dependencia de los agricultores del mercado, al que ahora debían acudir a comprar las semillas (Fitzgerald, 1986).Por entonces, los discursos desarrollistas posicionaban el avance de la ciencia y la tecnología como las claves para la solución de los problemas económicos y sociales. Retomaban enfoques surgidos en Estados Unidos al calor de la segunda posguerra, que proclamaban el subdesarrollo como resultado de un retraso evolutivo de estos países, a los que era necesario dotar de inversiones en ciencia y tecnología. Su expresión sectorial para el medio rural fueron las políticas derivadas de la revolución verde, que postularon la necesidad de "modernizar" el agro, diagnosticado como atrasado por su baja tecnificación. Junto a las trasformaciones productivas, se promovió un arquetipo social: la conversión de agricultores en empresarios racionales y eficientes. ${ }^{6}$ Para una provincia como Tucumán, atravesada por profundos procesos de concentración de la tierra en general y en la producción azucarera en particular, este acento iba a tener consecuencias vitales. En la Argentina, este discurso del desarrollo rural no estuvo acompañado por la alteración de los sistemas de propiedad ni de tenencia de la tierra.

En 1966 una nueva dictadura fue encabezada por el general Onganía. Por entonces, la economía tucumana atravesaba una fuerte crisis de sobreproducción azucarera. La respuesta gubernamental fue el cierre compulsivo de una serie de ingenios. La desocupación de cientos de trabajadores cañeros configuró entonces una aguda crisis social y un masivo éxodo rural (Bosi y Pucci, 2002). Paradójicamente, producto de la misma crisis, uno de estos ingenios devino en la cooperativa agrícola Campo de Herrera, que aún perdura. A lo largo de su extensa trayectoria, y pese a la escasa distancia que las separa, no ha tenido contacto significativo con 
la EEAOC (Gárgano, 2017b). La Estación Experimental reaccionó a la crisis impulsando la diversificación agrícola y la mecanización de la cosecha cañera, que hasta entonces era manual. No existieron en su interior investigaciones que incorporaran como problema el acceso a la tierra y la existencia de sujetos sociales agrarios por fuera de los grandes capitales. En línea con los enfoques productivistas del período, el eje en esta década continuó siendo el incremento de los rendimientos y la productividad de los principales cultivos sin explicitar a quiénes (a qué segmentos) servían estas investigaciones, y a quiénes dejaban fuera de la agenda.

Una década más tarde, durante la última dictadura (1976-1983), la EEAOC fue intervenida militarmente, aunque no experimentó cambios trascendentes en su organigrama. En este período la institución incorporó el nombre "Obispo Colombres", por el obispo José Eusebio Colombres (1778-1859), figura ligada históricamente tanto a la oposición al rosismo como a la promoción de la producción azucarera en la provincia (Juárez Dappe, 2010). Por entonces el espacio rural nacional experimentaba una serie de transformaciones. Luego de una primera recuperación alcanzada durante 1960, a lo largo de la década de 1970 el crecimiento de la producción agrícola pampeana se tornó vertiginoso, hasta alcanzar una cosecha récord a nivel nacional en 1984-1985 (Balsa, 2006: 133). ${ }^{7}$ Las principales políticas sectoriales del período apuntaron a eliminar las retenciones y las diferencias de cambio, liberalizar el comercio exterior y otorgar una reducción arancelaria a insumos clave (insecticidas, herbicidas, fertilizantes), y a desarticular las instancias regulatorias. Estas transformaciones incrementaron progresivamente la participación de los inversores financieros en el agro, dando impulso a los pools de siembra. La expansión de la frontera agrícola apuntaló un exitoso proceso de "modernización", cuya contractara fue el deterioro de las condiciones de vida y trabajo de los sectores más vulnerables. El sector pampeano lideró el proceso de concentración local y la creciente dependencia de insumos externos benefició a las empresas extranjeras.

Con la transición democrática iniciada en 1983, la EEOC sufrió la escasez de recursos de la mano del período hiperinflacionario. Durante la década de 1990 su situación presupuestaria se agravó, en pleno recorte neoliberal del aparato estatal, pero logró conservar un mecanismo propio de formación que le otorgó cierta continuidad al trabajo de sus técnicos e investigadores. Un sistema de pasantías y de becas internas, en tiempos en los que la cantidad de becas otorgadas por CONICET escasearon, le permitió consolidar una camada de profesionales que hicieron carrera en la institución y hoy coordinan áreas relevantes para su funcionamiento. En 1996 trabajaban cincuenta y tres personas.

Mientras que en las décadas de 1950 y 1960 las innovaciones tecnológicas asociadas al agro se destacaron por la difusión de maquinaria e implementos agrícolas, y las siguientes por la introducción de semillas mejoradas (de trigo, maíz, sorgo granífero y girasol), la década de 1990 se distinguió por la incorporación de la biotecnología, proceso que a nivel internacional venía desarrollándose con velocidad. En 1996, durante la segunda presidencia de Carlos Saúl Menem, su secretario de Agricultura, Ganadería y Pesca de la Nación, Felipe Solá, autorizó la introducción de una nueva variedad de soja en suelo argentino. Se trataba de la hoy famosa soja RR. Una variedad modificada genéticamente mediante la técnica de transgénesis con el objetivo de volverla resistente al herbicida glifosato, comercializado bajo la marca Round UpReady por la firma Monsanto (hoy fusionada con Bayer). Comenzaba un esquema productivo que iba a hacer de este cultivo un monocultivo en expansión, en lo que tiempo después sería caracterizado como un "desierto verde" (Teubal, 2001). La EEAOC no permanecería al margen.

\section{Soja Resistente a glifosato, marca nacional: MunasQa RR}

Las investigaciones y ensayos en el cultivo de soja fueron realizados durante más de cuarenta y cinco años en la EEAOC, pero recién a partir de 1996 sus investigadores profundizaron sus producciones (Devani, Ledesma, Lenis y Ploper, 2006).Los primeros estudios sobre el cultivo habían sido publicados por la Estación Experimental en una fecha muy temprana, 1912, alertando sobre su aptitud para los suelos del este y el sur tucumano. Durante las décadas posteriores no formó parte nodal de su agenda, hasta mediados de la década 
de 1960. En 1970 impulsó el cultivo en la región, que para entonces era prácticamente inexistente en el país. En esa etapa inicial produjo bebible de soja para ser distribuida en distintos hospitales, en asociación con el Ministerio de Salud Pública de la provincia. También intervino en la industrialización de harinas de soja para consumo y la extracción y purificación de aceites (Ploper, Fadda y Olea, 2009). Sin embargo, recién a fines de la década de 1990 intensificó las investigaciones. Precisamente en un momento en el que la oleaginosa ocupaba un lugar destacado en el esquema productivo local y la expansión de la superficie sembrada con soja transgénica se incrementaba a pasos agigantados. El mapa rural local estaba cambiando drásticamente.

En buena medida este nuevo escenario fue continuidad del proceso de agriculturización iniciado en la segunda mitad de la década de 1970, en tanto profundizó la expansión de la frontera agrícola y la desaparición de franjas de agricultores de menores recursos. Al mismo tiempo, supuso la irrupción de nuevas problemáticas sociales y ambientales. Como señalan Giarraca y otros (2005), el proceso de "sojización” daría paso a partir de esta década a una "agricultura sin agricultores". Las dislocaciones en la estructura social agraria que acompañaron este proceso incluyeron alteraciones en la organización del trabajo rural y una mayor concentración de la tierra. El aumento del contratismo, la desaparición de agricultores familiares, la extensión de los contratos accidentales como sistema de arriendo y la consolidación de la polarización social en el medio rural -producto del encarecimiento del paquete tecnológico básico-fueron algunas de sus consecuencias más visibles (Tort, 1983; Balsa, 2006).

En simultáneo, comenzaron a hacerse oír voces que, desde la sociedad civil, primero, y desde la academia, después, empezaron a cuestionar los daños en salud humana y en el ambiente derivados del uso de agrotóxicos asociados a los cultivos transgénicos, en particular al glifosato al que la soja RR es resistente. ${ }^{8}$ En un plano epistémico, la obtención de cultivos transgénicos también es señalada: se alerta sobre su identificación con procesos de simplificación teórica (en particular, en torno al concepto de gen) asociados a la omisión de riesgos potenciales (Francese y Folguera, 2018). Entre 1990 y 2011 el área sembrada con soja RR pasó de poco menos de 5.000.000 de hectáreas a casi 19.000.000, y la producción, de 10.862.000 toneladas a 40.100.197 (Gras, 2013, p.76). En Tucumán también se introdujo en la campaña 1996/97, y se expandió con igual velocidad. Mientras que en la campaña 1999/2000 ya ocupaba el $85 \%$ de la superficie sojera nacional, en el caso tucumano la superficie sembrada con soja transgénica pasó de 1.000 hectáreas en 1996/97 a 65.000 en la campaña 1999/2000 (Natera Rivas y Batista Zamora, 2005). Esta variedad se asoció así a la ampliación de la frontera agrícola hacia áreas hasta ese momento marginales para su cultivo. En el marco de este proceso, a partir del año 2000 la EEAOC produjo nuevas variedades de soja transgénica.

Munasqa RR fue desarrollada por el Programa Granos. En el 2001 se convirtió en la primera variedad de soja resistente al glifosato liberada por una institución estatal en la Argentina, y su alcance fue de gran repercusión en los productores del NOA y NEA (Tucumán, Salta, Chaco, Santiago del Estero) y norte de Santa Fe. De hecho, las redes de ensayo no se restringen a Tucumán: están ubicadas en Salta, Santiago del Estero, Catamarca. Poco tiempo después, su uso se extendió a Bolivia y Paraguay, donde fue liberada en 2006. También a Sudáfrica, donde la inscripción de las variedades de soja de la EEAOC se realiza a través de la empresa Sensako. Las principales características de Munasqa radican en su adaptación a períodos de estrés hídrico, buen comportamiento al vuelco, bajo desgrane y resistencia a algunas enfermedades propias del NOA, como "cancro del tallo", "mancha ojo de rana", "tizón bacteriano" y "mildiu" (EEAOC, web). Uno de los investigadores del Programa señala al respecto:

Munasqa fue la primera variedad de soja resistente al glifosato que fue obtenida por una institución oficial, todo el resto venía de empresas privadas. Realmente ha sido interesante el aporte que se pudo hacer desde acá, y poder llevar tecnología de Argentina a otros países como Bolivia, donde ocupa más del $50 \%$ de la siembre de soja. Desde ese lado la institución aporta no solamente para la región o para el país, inclusive para los países limítrofes (Ledesma, entrevista, 2016).

Por su parte, el director de la EEAOC enfatiza: 
Somos una institución pública. El financiamiento viene del sector privado, pero al ser retenidos esos fondos por ley, somos públicos. Porque es compulsiva la retención, es por ley. Entonces son fondos públicos, se tienen que manejar como todo fondo público. Esa es la fortaleza de esta articulación pública- privada (Ploper, entrevista, 2016).

En el primer discurso del investigador aparece una oposición con el sector privado, remarcando como rasgo distintivo positivo que Munasqa es una variedad producida en "una institución oficial", a diferencia del resto de las variedades RR, obtenidas por empresas. La obtención de esta variedad es presentada como un rasgo diferenciador, que podría dar a entender que estos dos sectores persiguen objetivos distintos. Al mismo tiempo, en el relato del director de la EEAOC lo que se rescata es la articulación entre ambos sectores, "público" y "privado", en línea con los propios fundamentos presentes en el relato de la historia de la institución. Así, la distancia (que diferencia con claridad lo producido en esta institución de lo generado por las empresas) o la cercanía (la "cooperación público-privada", el trabajo en pos de necesidades productivas "concretas") es presentada alternativamente en función del contexto. En este sentido, la definición de "público" que aparece parece restringirse a su sello y espacio institucional ("una institución oficial”). No está definido por las necesidades o problemáticas atendidas, que son corporativas, en tanto responden mayoritariamente a un único segmento dentro del sector rural. En cuanto al aporte institucional, se destaca que éste consiste en "llevar tecnología argentina a otros países", como Bolivia. La cuestión nacional, así, aparece resaltada. En el mismo sentido, para el $110^{\circ}$ aniversario de la institución se destacaba entre sus logros "Desarrollar una variedad de caña de azúcar transgénica con resistencia a glifosato, el primer desarrollo transgénico producido íntegramente en el país". 'Ahora bien, en tanto tal, este "desarrollo nacional" no se mide en función de las problemáticas, económicas, sociales o ambientales que pueda generar o resolver, sino según el pretendido origen de la tecnología difundida. Así, tampoco se cuestiona cuáles son las problemáticas que exportamos bajo esta supuesta soberanía tecnológica.

A su vez, en esta construcción, la retórica que equipara "público" a "estatal” omite precisar cuál es el rol del Estado en este esquema productivo en general, y en la producción científico-tecnológica analizada en particular. Mientras que el eje de lo público podemos entenderlo como un ámbito de lo común, donde están incorporadas necesidades y problemáticas ligadas al bienestar de las poblaciones implicadas, la agencia estatal en este proceso tiene otra significancia. Como señala Manzanal (2012) respecto al desarrollo rural, Argentina comparte con otros países de la región un modelo de desarrollo de carácter extractivista, concentrador y excluyente, en el que resulta vital el accionar del binomio que construyen capitales transnacionales y gobiernos locales. Si analizamos el proceso de producción de conocimientos, el binomio se amplía: Estado, empresas y científicos operan en un mismo entramado.

$\mathrm{Al}$ igual que en otros programas de mejoramiento, las nuevas líneas de variedades son inscriptas en el Instituto Nacional de Semillas (INASE) y deben pasar por instancias regulatorias de control para su aprobación. En estas instancias, el Estado asume una lógica empresarial. Por otro lado, si bien permanecen como propiedad intelectual de la institución, frecuentemente son vendidas mediante convenios de vinculación tecnológica con empresas privadas a las que se les cede la explotación comercial. Esto es visto como una solución a la falta de capacidades propias. En tanto, como señala uno de los investigadores del Programa, una vez obtenido el producto "no tenemos la capacidad para hacer la multiplicación a gran escala. Por eso la necesidad de asociarnos con empresas que lo comercializan". Como sucede con el funcionamiento integral de la EEAOC, el Programa Granos, y dentro de él las investigaciones en soja, se financian primordialmente vía la retención que se les efectúa a los productores de un porcentaje (el 0,5\%) de la comercialización. Al mismo tiempo, las variedades generadas, como Munasqa $R R$, producen un ingreso que también se destina a financiar las investigaciones. Una tercera vía es aportada por el gobierno provincial. En rigor, el financiamiento estatal indirecto es más amplio, ya que buena parte de los becarios e investigadores dependen del CONICET. Finalmente, el programa ofrece servicios pagos a terceros que también son parte de su financiamiento, por ejemplo evaluación de cultivares para distintas semilleras. 
Como señalamos, la variedad analizada fue producida a partir de la soja RR ya existente y luego fue liberada. En este punto, cabe recuperar algunas de las referencias mencionadas en un inicio con respecto al rol del Estado en la producción de ciencia y tecnología. Mientras que, en Europa y Estados Unidos, el boom entusiasta de posguerra estuvo marcado por el financiamiento estatal del desarrollo científico y tecnológico, a partir de la década de 1970 tanto el financiamiento como el control de la CyT se desplazó a manos privadas (Dickson, 1988). En la periferia, ni el boom desarrollista tuvo el mismo impacto, ni la inversión privada en CyT desplazó nunca en magnitud a la estatal. Sin embargo, el control privado de la actividad científica y tecnológica contó con el Estado para su funcionamiento. Y, del mismo modo que décadas atrás la importación del modelo lineal configuró la orientación de las políticas científicas locales, desde mediados de la década de 1990 lo hizo la adopción (fallida) del concepto de Sistema Nacional de Innovación (SNI). Freeman (1987) y Lundvall (1992) lo definieron como una red integrada compuesta por instituciones del sector privado y público que producen, trasmiten y difunden nuevas tecnologías. A diferencia del modelo lineal, este esquema propuso un conocimiento a demanda, con eje en la capacidad empresarial y en la "cooperación públicoprivada”. Sin embargo, estas políticas científicas comparten con las previas el carácter dependiente hacia afuera, en tanto continúan promocionando recetas generadas en potencias centrales que deberían solucionar los problemas de la periferia y la falacia de un supuesto desarrollo que no sólo no es tal (pese a las retóricas, se exporta una tecnología ya generada previamente), sino que potencia graves conflictos sociales y ambientales.

¿Qué rol juegan, entonces, los conocimientos científicos y tecnológicos en la actual forma de explotación y producción del agro argentino? El caso mencionado de la soja RR no es menor, considerando la velocidad y el volumen de su expansión. Al mismo tiempo, es ilustrativo de un modo de organizar la producción científica y tecnológica que lo excede ampliamente. El agronegocio supone una forma de organización de la producción agrícola basada en el empleo de biotecnologías, un intenso ritmo de innovación tecnológica, altos requerimientos de capital, participación creciente del capital financiero y reorganización del trabajo y de la producción (Gras y Hernández, 2013, pp. 74, 75). Por esto, el rol de los saberes científicos y tecnológicos implicados es clave. Como enfatizamos, esta reorganización productiva también está ligada a la profundización e irrupción de profundos problemas ambientales y sociales. ¿No resulta vital, entonces, cuestionar la ligazón entre estos conocimientos implicados, su forma de producción y dichas problemáticas?

Desde la revolución verde en adelante los procesos de obtención de semillas modificadas (por entonces, en su mayoría variedades híbridas) han intensificado en forma sincrónica el rol creciente de las innovaciones científicas y tecnológicas, y la exclusión de las voces de las comunidades rurales directamente implicadas. Mientras que en el pasado el aumento de los rendimientos agrícolas estuvo acompañado de un notable incremento de la dependencia de los agricultores respecto del mercado, en la actualidad la conformación de paquetes tecnológicos cerrados (compuestos por semillas modificadas, insumos a los que son resistentes y prácticas de siembra como la siembra directa) coarta su autonomía y fomenta la desaparición de aquellos sujetos sociales agrarios que no pueden acceder a ellos. Se construye así un circuito que posee una dinámica virtuosa en términos de rentabilidad esperada y generación de nuevas investigaciones, cuyo reverso es igualmente potente en términos ambientales y sociales, aunque con signo opuesto. Las resistencias de los cultivos a determinadas enfermedades o malezas que son generadas son acompañadas de otras resistencias y sensibilidades no buscadas originalmente, provocadas usualmente por el uso intensivo de agrotóxicos, que son resueltas con un nuevo producto combinado (semilla modificada, asociada por su resistencia a determinado insumo). Se construye así un paquete tecnológico cerrado y un círculo comercial al mismo tiempo. En ese esquema, los efectos no deseados (por ejemplo, una nueva resistencia), lejos de ser un problema, amplían el alcance del paquete en ambos sentidos (técnico y mercantil).

$\mathrm{Al}$ mismo tiempo, mientras que en el pasado los enfoques propios de la modernización agrícola de las décadas de 1950 y 1960 postularon la necesidad de cambiar la mentalidad del agricultor, desde fines de la década de 1970 esta idea fuerza se inscribió plenamente en la lógica mercantil y en la reconfiguración de un espacio rural signado por la concentración de capital y la polarización social (Gárgano, 2017a). En la 
actualidad persiste el fomento a una nueva cultura emprendedora y una justificación cercana al determinismo tecnológico, que asocia linealmente mayor difusión tecnológica, mejores rendimientos y elevación del nivel de vida de la población. Así, los programas de investigación de la EEAOC se organizan en función de los principales cultivos de la zona(caña de azúcar, citrus y granos) y, según explican sus investigadores, su objetivo fundamental es "aumentar la productividad de los cultivos de la región" (Ledesma, 2016, entrevista). Cabe preguntarnos: ‘a quién beneficia este objetivo general y la generación de una nueva variedad de soja transgénica en particular? Las dimensiones epistemológicas implicadas (cómo se construyen los objetos de estudio, qué ramas del conocimiento intervienen y bajo qué jerarquías, qué criterios se aplican) resultan indisociables de las políticas y económicas. Mientras que es posible distinguirlas en forma analítica, en la práctica operan en conjunto. La elección de una técnica, en este caso la transgénesis, y en términos más generales la definición de la agenda de investigación, habilitan determinados intereses sociales y económicos como prioritarios y omite otros.

\section{Conocimiento ¿Útil? AUtopercepciones de la CIENCIA EMPRESARIAL}

El 103 aniversario de la EEOC incluyó una serie de festejos, en los que participó el entonces ministro de Ciencia, Tecnología e Innovación Productiva de la Nación. En esa ocasión, el ministro remarcó que se trataba de una institución "emblema de un cambio a seguir". ${ }^{10}$ Más específicamente, afirmó que estaba ante una "institución ejemplo" para todo el país que había sabido dar "soluciones concretas a problemas de la producción". ${ }^{11}$ En el acto participaron funcionarios públicos, directivos de la Estación Experimental y empresarios del sector, entre ellos el públicamente reconocido Gustavo Grobocopatel. El apoyo no fue meramente retórico. En 2002 el personal pasó de cincuenta y tres a noventa y seis miembros, en la actualidad el plantel lo componen más de cuatrocientas personas. A su vez, hoy es parte de una Unidad Ejecutora de CONICET de doble dependencia: ITANOA. Según Daniel Ploper, investigador de CONICET y director de la EEAOC, este crecimiento tuvo que ver con el escenario productivo en tanto "En el 2003 se reactivó la industria, se reactivó el campo" (Ploper, 2016, entrevista). La definición de las agendas de investigación a partir de este contexto es relatada remarcando su función de generar ciencia y tecnología "a demanda". Esta caracterización coincide con el esquema señalado anteriormente, motorizado por la promoción de una retórica centrada en el impulso a un Sistema Nacional de Innovación. Al mismo tiempo, da cuenta de cómo éste opera en la periferia:

Nosotros acá hacemos investigación por demandas, no investigación por oferta. Otras instituciones, las universidades y el mismo CONICET, trabajan por investigación por oferta. Acá vienen los señores y dicen que acá hay que investigar sobre esto, esta es la prioridad que tenemos. Y estos señores, como digo, se reúnen todas las semanas... Ni el mismo consejo directivo del INTA tiene ese poder. Acá tiene poder absoluto el directorio, no hay línea que valga, ellos deciden y bajan las instrucciones (Ploper, 2016).

Esta forma de organizar las prioridades de investigación, mientras es presentada como un rasgo valioso y diferenciador (a diferencia de otros organismos, "aquí se produce a demanda"), nos brinda herramientas para comprender cómo opera la alianza entre expertos y no expertos que sostiene el tipo de ciencia y tecnología producidas. Así, en palabras de una investigadora, "cómo se define la agenda de la investigación básicamente viene por una cuestión de demanda de los productores”. ¿Quiénes son, entonces, los “no expertos" que están representados y habilitados a tomar decisiones dentro de la Estación Experimental? Se trata de representantes de los poderes fácticos de la dinámica productiva local. El Directorio cuenta con dos representantes de la producción de cañera, dos del sector industrial azucarero, uno por los plantadores del citrus, otro por la industria cítrica, un séptimo representante por granos, otro por actividades ganaderas, un representante por agricultores tabacaleros y el décimo en representación del sector de horticultura. En resumen, el directorio lo integran representantes de los principales capitales agroindustriales de la región. No casualmente, de los 
diez integrantes cuatro pertenecen al sector azucarero, actividad que históricamente ha concentrado las principales ganancias de la provincia. Como señala la investigadora, dentro de la EEAOC sus integrantes consideran que "se trabaja para resolver, y esa es un poco la filosofía de la estación, resolver las problemáticas del sector agro-industrial” (Fogliata, 2016, entrevista).

Este sesgo no se limita a la construcción de las agendas "duras". Si se observan los contenidos del área de Economía, abunda la generación de datos estadísticos, valores brutos e información de costos. Investigaciones centradas tranqueras adentro, sin conexión con las problemáticas económicas y sociales del espacio rural local, ni de su articulación con otros espacios. La provincia de Tucumán tiene una población de.592.878 habitantes (INDEC, 2015). Un informe oficial del 2016 sobre la situación socio-económica de la provincia señala que la situación social refleja diversas deficiencias; en especial, los indicadores asociados a calidad de vida (red de gas, desagüe de red, capacidad de subsistencia) y sanidad (tasa de mortalidad infantil y materna, población no cubierta por obra social, nacidos vivos con bajo peso al nacer) resultan superiores al promedio nacional (MinEco, 2016). En este marco, atravesado por una serie de problemáticas que reflejan la existencia de necesidades vitales insatisfechas, la informalidad del empleo se destaca con una tasa del $44,7 \%$, superior a los niveles nacionales del 36,4\%. El sector agroindustrial es uno de los que registra mayores irregularidades (MinEco, 2016). Por ejemplo, la producción azucarera está concentrada en 15 ingenios en los que el grado de informalidad es de los más elevados de la provincia. En este sentido, cabe cuestionar: ¿por qué no es pertinente que la agenda de estudios de Economía agraria de un organismo estatal contemple problemáticas tales como el acceso a la tierra, las condiciones de habitabilidad y ocupación, su vinculación a los patrones productivos de la provincia? Nuevamente, su ausencia se explica por las características de la alianza entre conocimientos expertos, encarnados por científicos y técnicos del ámbito estatal, y no expertos, que representan a los principales capitales agrarios. En este sentido, a pesar de la incidencia de voces ajenas al campo científico, no estamos frente a un caso de incidencia social en las agendas de investigación, en un sentido democratizador como el propuesto por Illich (2006), sino más bien todo lo contrario. No hay presencia de sujetos sociales agrarios desplazados (productores familiares, asalariados rurales, población urbana desplazada, arrendatarios y un largo y heterogéneo etcétera) a quienes el incremento en los rendimientos producidos y exportados no modifica sus condiciones de existencia, ni se vincula a sus necesidades y realidades. Así, la exclusión de estas voces en la definición de los objetivos de las agendas de investigación es simultánea a la exclusión de determinadas ramas del conocimiento y enfoques, la jerarquización de objetos de estudio y la construcción de determinados problemas y soluciones.

Por otro lado, en línea con lo señalado previamente, una de las validaciones que se registran en los discursos de los integrantes de la EEAOC remite a su aporte en tanto producción nacional. Así, en el mismo aniversario aludido al inicio destacaban: "Somos internacionales porque, entre otras cosas, tenemos nuestras primeras variedades de soja en Sudáfrica, Bolivia y Brasil” (MINCyT, 2016, énfasis propio). Nuevamente, problemáticas ligadas a la soberanía tecnológica y la exportación de tecnologías locales aparecen dentro de las justificaciones. Y una vez más se habilita el interrogante. ¿Qué implicancias deseadas tendría un desarrollo tecnológico nacional? ¿Cómo podemos medirlo? ¿En función de la resolución de problemáticas locales, de respuestas a condiciones de vida de las poblaciones implicadas? Si ése fuera el caso, de mínima quedan dudas sobre el carácter sesgado de la consideración que se hace de éstas.

Retomando el análisis de Pestre (2005) esbozado en el inicio de este artículo, es posible observar que desde sus orígenes el conocimiento producido en la EEAOC fue de gran interés para los poderes políticos y económicos, y estuvo tempranamente articulado a la producción. Al mismo tiempo, a diferencia del típico discurso de la "ciencia pura" construido en instituciones académicas por los propios científicos durante el siglo XIX, las vías de legitimación dentro de la EEAOC desde sus comienzos estuvieron asociadas a su capacidad de brindar soluciones concretas, rasgo que tiene una plena actualidad en los discursos presentes. Sin embargo, esta definición no obstaculizó la (auto)construcción de sus científicos y técnicos como políticamente irresponsables. Mientras que el cientificismo cumplió una función ideológica clave 
garantizando que los científicos no fueran considerados "responsables de los malos usos que se hicieran de sus descubrimientos” (Pestre, 2005: 29), la legitimación registrada centrada en la eficiencia práctica también permite sostener la escisión entre los contenidos de las investigaciones, la omisión de sus efectos potenciales y su vinculación a problemáticas sociales y ambientales. Si en este espacio, a diferencia de otros ámbitos, el relato de la ciencia pura no fue ni es dominante, las justificaciones y validaciones del accionar de la EEAOC comparten con él una misma función ideológica. La de sostener y reactivar la escisión entre objetos y sujetos que conocen el mundo, la presentación de los resultados de las investigaciones como escindidos de intereses económicos, disputas políticas y sistemas de valores, y en consecuencia, como socialmente neutros. Estas validaciones en apariencia se encuentran muy distantes de los relatos cientificistas que reclamaban para sí una autonomía de otras esferas y se proclamaban carentes de intereses, en tanto asumen como valores positivos la generación de conocimientos "a demanda", "útiles", no producidos en torres de marfil sino en función de "necesidades concretas del sector". Sin embargo, logran la misma operación: ocultar que son producto de una disputa social saldada en favor de intereses hegemónicos y que cumplen el rol de legitimarlos y reproducirlos.

\section{CONCLUSIONES}

La existencia de una ciencia empresarial, orientada por criterios de mercado y regida bajo la lógica del capital, puede rastrearse muy atrás en el tiempo. En las últimas décadas, ha experimentado transformaciones profundas en sus prácticas. Es decir, en los modos de hacer ciencia, en los actores que intervienen y en las formas de apropiación de los saberes producidos, cuyo resultado fundamental es la transformación del conocimiento en mercancía, con sus respectivas implicancias para la vida. Dentro de las investigaciones orientadas al medio rural este carácter tiene un rol fundamental, en tanto la naturaleza mercantilizada \#devenida commodity\# es conocimiento-intensiva. Esto se explica por el rol fundamental que ocupan los conocimientos científicos y tecnológicos en la obtención de nuevas semillas, prácticas agronómicas y productos asociados a ellas.

Dentro de la trayectoria histórica de la EEAOC, ámbito de investigación y desarrollo tecnológico rural pionero en la Argentina, la concepción de lo que fue considerado un conocimiento útil fue variando a lo largo del tiempo. En este largo tránsito, fue posible identificar continuidades y rupturas a partir de algunos hitos y de las dinámicas socio-económicas implicadas. Así, desde sus orígenes, en tiempos de creación de la Estación Experimental, esta utilidad se articuló directamente a los intereses de empresarios azucareros y funcionarios políticos, cuyo solapamiento era frecuente, como lo expresa el caso del primer presidente de la institución. Para 1946, a partir de la intervención peronista, la noción de conocimiento útil parece haberse alineado a la necesidad de incrementar los niveles de productividad que demandaban los planes quinquenales. Durante la década de 1960, se ancló a las necesidades marcadas por la exportación de la revolución verde y a la adopción local de los patrones productivos, tecnológicos y teóricos que la acompañaron. Al mismo tiempo, en el plano regional se articuló a la fuerte crisis de la industria azucarera, que llevó a fomentar una diversificación agrícola. Desde mediados de 1970 y durante la década de 1980, se asoció a los drásticos y asimétricos cambios que atravesaron el espacio rural, a la reorientación de las políticas sectoriales en tiempos de la última dictadura y también a la creciente tendencia internacional de privatización de la ciencia y la tecnología.

A partir de mediados de la década de 1990 la concepción de un conocimiento útil se articuló fuertemente al esquema del agronegocio, en el que las investigaciones en soja cobraron un lugar destacado que aún mantienen. La ciencia “a demanda”, presente en las recetas de los célebres sistemas nacionales de innovación, continuó configurando ausencias en la definición de qué fue entendido por las necesidades del sector, que dejaron fuera de agenda a los sectores más vulnerables del agro. A diferencia de lo sucedido en las tres décadas previas, entre 2003 y 2015 la participación estatal en términos de aporte presupuestario al funcionamiento de la institución, y del área de ciencia y técnica en términos generales, aumentó notablemente. No solamente en forma indirecta, a través del incremento de becarios e investigadores aportados por el CONICET, sino 
también a partir de la transformación de la institución en Unidad Ejecutora. Este incremento de la presencia estatal no se vio acompañado, sin embargo, por un cambio o ampliación de su orientación tradicional. En definitiva, qué fue considerado un conocimiento científico útil cambió a lo largo del tiempo.

A lo largo de esta trayectoria, fueron generándose una serie de validaciones y justificaciones del accionar de la EEAOC que configuraron una noción hegemónica de la utilidad del conocimiento allí producido a partir de una alianza entre saberes expertos y no expertos, y sujetos colectivos e individuales que los encarnaron. Esta operación comparte con aquella propia de la "ciencia pura" su carácter de indiscutible "principalmente para los profanos" (Pestre, 2005, p. 29). Sin embargo, en este punto es necesario remarcar una salvedad sustancial. Por "profanos" aquí no es posible ubicar al conocimiento no experto en general, habitualmente presentado en tensión (o colonizado por) saberes expertos. Ya que no son (solamente) expertos quienes intervienen, inciden, proponen y digitan las agendas de la Estación Experimental. Se trata de voces no expertas, pero sí representantes de los poderes locales. Encontramos, entonces, una alianza, mediada por la agencia estatal, entre los conocimientos no profesionales que portan estos actores y los saberes profesionales desplegados por los científicos y técnicos de la EEAOC. En términos de Illich (2006), podemos considerar este caso como un ejemplo "al revés" de participación ciudadana en materia de ciencia y tecnología. Es decir, se produce una articulación entre saberes expertos y no expertos, pero estos últimos responden a intereses corporativos hegemónicos. En esta alianza el Estado ocupa un rol destacado, garantizando la conexión y produciendo una ciencia empresarial en la que muchos otros saberes y sujetos quedan desplazados. El alcance de estas validaciones no es solamente simbólico; tiene consecuencias materiales directas en las formas de organización de los suelos, las semillas, las producciones, todo un mundo vital, del que la voz de las poblaciones implicadas es excluida. Así, las expresiones locales del otro campo que subsiste a la sombra de los grandes capitales agrarios no tienen lugar ni en la definición de las prioridades de las investigaciones, ni en sus contendidos.

¿Qué nos dice esta trayectoria del mapa actual de la producción de ciencia y tecnología? Poco si es pensada en función de sus especificidades. Sin embargo, las problemáticas transversales que recorre generan, al menos, una señal de alarma a la hora de identificar cuáles son los criterios y los objetivos implicados, qué relación tienen con el patrón de acumulación local, cómo se produce \#en definitiva\# una ciencia empresarial. Esta trayectoria histórica aporta a la reflexión en torno al sentido y la naturaleza de los cambios en las prácticas científicas de las últimas décadas, en los que se inscribe. Y apunta a comprender cuáles son los intereses a los que responde la construcción social de la imagen de la ciencia hoy dominante y cuáles sus implicancias políticas, éticas, económicas, ambientales.

También abre el interrogante sobre la posibilidad de hacer ciencia a contramano de los poderes hegemónicos. En particular en relación con el carácter estatal del espacio analizado, actualiza la necesidad de entender a los científicos involucrados como parte de la burocracia estatal. $Y$ en tanto tal, como "arena movediza”, expresión material del Estado, brazo ejecutor de sus políticas y resultado de las disputas que se libran en su seno. Así, las instituciones, y quienes las componen, son agentes activos en la resolución de esos conflictos. En otras palabras, las instituciones estatales "no sólo son actores políticos, sino que además su ámbito de acción constituye un terreno de lucha" (Oszlak, 2015, p. 325). A su vez, al identificar una alianza de carácter corporativa y hegemónica entre saberes expertos y no expertos, su registro también valida la potencial existencia de otras articulaciones de saberes en las que se expresen intereses colectivos. En otras palabras, evidencia que pueden establecerse diálogos entre distintos tipos de conocimientos y a su vez señala que el carácter que adquiera esta definición es político, y como tal depende de las relaciones de fuerza que logren establecerse.

Este análisis también nos permite analizar el rol del Estado en la mercantilización de la tecnociencia. En particular, su promoción de una agenda científica y tecnológica articulada al proceso local de acumulación de capital. Mientras que ésta es su resultante, también fue un insumo fundamental para la configuración de este esquema productivo. En este punto, como señalamos al indagar en una de las agendas de investigación de la EEAOC centrada en la obtención de una variedad de soja transgénica, las dimensiones epistemológicas 
implicadas (cómo se construyen los objetos de estudio, qué ramas del conocimiento intervienen y bajo qué jerarquías, qué criterios técnicos se aplican, etc.) resultan indisociables de las políticas y económicas. Mientras se elaboran explicaciones lineales, se produce una ciencia que poco tiene que ver con las necesidades colectivas de los territorios locales. La producción y apropiación de resultados de investigación se presenta, así, como parte constitutiva de un patrón de acumulación de corte extractivista, con sus respectivos costos para la sociedad y el ambiente (Gárgano, 2018). En este sentido, es posible identificar tres elementos fundamentales del rol estatal en este accionar: a) garantiza las rentas privadas; b) opera en un trinomio Estado-científicosempresas; c) constituye una arena en disputa, signada por una heterogeneidad asimétrica.

Finalmente, cabe preguntarnos a partir del recorrido trazado: mientras que el cientificismo proclamaba a la ciencia como exenta de valores e intereses, esta ciencia empresarial ¿qué valores construye? ¿Qué nociones de "problema", "necesidad" y "solución" motoriza? Aquí es posible ubicar un doble desplazamiento de los discursos y de las prácticas científicas. A diferencia del relato propio de la "ciencia pura", las retóricas analizadas incorporan la "eficacia magnetizable y pragmáticamente concebida" (Pestre, 2005: 31) como un valor que justifica y a la vez valida el quehacer científico y técnico, sin embargo la opacidad y el carácter (supuestamente) aséptico se trasladan a sus "usos". Así, desde los orígenes de la institución no se apela a la creación del conocimiento por el conocimiento mismo, sino que, por el contrario, los objetivos pragmáticos son incorporados en forma explícita como valores y principios rectores de la organización de la producción científica y tecnológica. No obstante, la opacidad está presente al difuminar el rol de esos mismos saberes en los esquemas productivos, con sus correspondientes procesos de obtención de ganancias, y en las problemáticas en salud y en ambiente a las que han sido asociadas, lo que genera una aparente irresponsabilidad en torno a las implicancias políticas, económicas, ambientales y éticas de los conocimientos producidos.

Mientras que el despliegue de conocimientos propio de la colonización de la ciencia moderna estuvo asociado a una redefinición del orden social, en la actualidad su configuración tiene que ver con la profundización de éste y con la ampliación del rol de la ciencia y la tecnología como elementos vitales para su desarrollo. La articulación entre ciencia, tecnología y capital tiene, simultáneamente, una actualidad y una intensificación en su interacción. En el espacio y caso analizado, la mercantilización de la ciencia y la tecnología implica que estos conocimientos constituyen insumos nodales del agronegocio.

Analizar críticamente esta organización de la producción del conocimiento se nos presenta como una vía de desnaturalización de aquello que es presentado como aparente necesidad y horizonte deseado. Antes que una solución y un punto de llegada, esta noción hegemónica de conocimiento útil es parte fundamental del problema. Desarmarla constituye un punto de partida posible para transitarlo.

\section{ENTREVISTAS CONSULTADAS Y/O CITADAS}

Ing. Agr. Fernando Ledesma, investigador de la EEAOC, integrante del Programa Granos. San Miguel de Tucumán, febrero 2016.

Ing. Agr. Patricia Digonzelli, investigadora de la EEAOC, referente del trabajo enmarcado en el PROICSA. San Miguel de Tucumán, febrero 2016.

Ing. Agr. Julia Figueroa, investigadora de la EEAOC, responsable del Centro de Saneamiento de Citrus. San Miguel de Tucumán, febrero 2016.

Dr. Atilio Pedro Castagnaro, Investigador Principal del CONICET, director de ITANOA (Unidad Ejecutora de doble dependencia). San Miguel de Tucumán, febrero 2016.

Ing. Agr. Gabriela Fogliata, jefa del área de Fitopatología de la EEAOC. San Miguel de Tucumán, febrero 2016.

Romina Bertani, becaria doctoral del CONICET en el área de Fitopatología de la EEAOC. San Miguel de Tucumán, febrero 2016. 
Paula Claps, becaria doctoral del CONICET en el área de Fitopatología de la EEAOC. San Miguel de Tucumán, febrero 2016.

Dr. Ing. Agr. Daniel Ploper, director técnico de la EEAOC, Investigador Principal de CONICET. San Miguel de Tucumán, febrero 2016.

\section{ReFERENCIAS}

Alemany, C. E. y Sevilla Guzmán, E. (2007). ¿Vuelve la extensión rural?: Reflexiones y propuestas agroecológicas vinculadas al retorno y fortalecimiento de la extensión rural en Latinoamérica. Realidad Económica, 227, 52-74. Recuperado de http://www.iade.org.ar/articulos/vuelve-la-extension-rural-reflexiones-y-propuestas-agroecolog icas-vinculadas-con-el

Arancibia, F. (2013). Controversias científico-reguladoras y activismo: el caso de los agroquímicos para cultivos transgénicos en Argentina. En F. Tula Molina y A. Vara (Comps.), Riesgo, politica y alternativas tecnológicas (pp. 309-358). Buenos Aires: Prometeo.

Balsa, J. (2006). Los sujetos sociales de la expansión agrícola en las décadas de 1970 y 1980. En El desvanecimiento del mundo chacarero. Transformaciones sociales en la agricultura bonaerense 1937-1988 (pp. 133-161). Bernal: Universidad Nacional de Quilmes.

Barañao, L. (2012). La nación difundirá el modelo de la EEAOC a toda la Argentina. (28 de julio 2012). La Gaceta, p. 15. Recuperado de https://www.lagaceta.com.ar/nota/502931/economia/nacion-difundira-modelo-eeaoc-t oda-argentina.html

Blois, M. P. (2016). Ciencia y glifosato: interpelando órdenes. Una investigación en la prensa en el contexto argentino. Cuadernos de Antropología Social, (43), 73-93. Recuperado de https://www.redalyc.org/pdf/1809/180948645 007.pdf

Bolsi, A. y Pucci, R. (1997). Evolución y problemas de la agroindustria del azúcar. En A. Bolsi (Dir.) Problemas agrarios del Noroeste argentino (pp. 113-133). San Miguel de Tucumán: Universidad Nacional de Tucumán.

Devani, M., Ledesma, F., Lenis, J. y Ploper, D. (Eds.) (2006). Producción de Soja en el noa. San Miguel de Tucumán: Estación Experimental Agroindustrial Obispo Colombres.

Dickson, D. (1988). The new politics of science. Chicago: Universidad de Chicago.

Djenderedjian, J. (2014). El Estado, presente Aproximación a las políticas gubernamentales de desarrollo tecnológico, investigación y extensión rural en la argentina de finales del siglo XIX e inicios del XX. Revista de Historia Americana y Argentina, 49(2), 77-110. Recuperado de http://ref.scielo.org/m5tzz8

Echeverría, J. (2003). La revolución tecnocientifica. Madrid: Fondo de Cultura Económica.

Estación Experimental Agroindustrial Obispo Colombres. Productos: Munasqa RR. Recuperado de http://www.eea oc.org.ar/productos/2/Munasqa-RR.html

Faiguenbaum Chame, S. (2011). ¿Ciencia o politica pública? Cuatro décadas de investigación agropecuaria del INIA. Santiago de Chile: Consejo Nacional de la Cultura y las Artes.

Fitzgerald, D. (1986). Exporting American Agriculture. Social Studies of Science, 16, 457-483. Recuperado de https:/ /doi.org/10.1177/030631286016003003

Francese, C. y Folguera, G. (2018). Saberes simplificados, tecnociencia y omisión de riesgos. El caso de los organismos genéticamente modificados. RUNA, 39(2). Recuperado de http://revistascientificas.filo.uba.ar/index.php/run a/issue/current/showToc

Freeman, C. (1987). Technology, policy, and economic performance: lessons from Japan. Londres: Pinter.

Gárgano, C. (2017a). Rupturas y continuidades en el perfil de la extensión rural argentina. Quinto Sol, 21(2). Recuperado de http://cerac.unlpam.edu.ar/index.php/quintosol/article/view/999 DOI: http://dx.doi.org/10 $.19137 /$ qs.v21i2.999 
Gárgano, C. (2017b). Campo de Herrera: historia en el surco del cañaveral. Investigación, extensión y autoorganización rural. Trabajo y Sociedad, 29, 121-137. Recuperado de https://www.unse.edu.ar/trabajoysociedad /29\%20GARGANO\%20CECILIA\%20Campo\%20de\%20Herrera.pdf

Gárgano, C. (2018). Ciencia, Tecnología y Mercado: Investigaciones en arroz en el INTA argentino. Journal of Technology Management \& Innovation, 13(1), 75-83. Recuperado de http://www.jotmi.org/index.php/GT/ar ticle/view/2425

Giarracca, N., Aparicio, S. y Gras, C. (2001). Multiocupación y pluriactividad en el agro argentino: el caso de los cañeros tucumanos. Desarrollo Económico, 41(162), 305-320. Recuperado de https://www.jstor.org/stable/3455990

Gibbons, M., Limoges, C.,Nowotny, H., Schwartzman, S., Scott, P. y Trow, M. (1994). The new production of knowledge. The Dynamics of Science and Research in Contemporary Societies. Londres: Sage Publications.

Graciano, O. F. (1998). Universidad y Economía agroexportadora: el perfil profesional de los ingenieros agrónomos, 1910-1930. En N. Girbal Blacha (Comp.), Agro, universidad y enseñanza. Dos momentos de la Argentina rural (1910-1955) (pp. 13-72). La Plata: Universidad Nacional de La Plata.

Graciano, O. (2017). Ciencia, profesión académica y burocracia en el Estado Liberal. La genética vegetal y la gestión de la agricultura. En M. S. Di Liscia y G. Soprano (Eds). Burocracias estatales. Problemas, enfoques y estudios de caso en la Argentina (entre fines del siglo XIX y XX) (pp. 163-186). Rosario: Prohistoria.

Gras, C. y Hernández, V. (2013). (Coord.) El agro como negocio. Producción, sociedad y territorios en la globalización. Buenos Aires: Biblos.

Gras, C. (2013).Expansión agrícola y agricultura empresarial: el caso argentino. Revista de Ciencias Sociales, 26(32), 73-92. Recuperado de https://www.redalyc.org/pdf/4536/453644793005.pdf

Illich, I. (2006). Obras Reunidas (Vol. 1). México: Fondo de Cultura Económica.

INDEC (2015). Censos Nacionales de Población, Hogares y Vivienda. Buenos Aires: INDEC.

Juárez-Dappe, P. (2010). When Sugar Ruled.Economy and Society in NorthwesternArgentina, Tucumán, 1876-1916. Athens: Ohio University Press.

Kreimer, P. (2001). Ciencia y actores sociales: la ruptura de los modelos lineales y sus implicaciones éticas. En Ética y ciencia. Programa de Divulgación Cientifica (pp. 61-76). Córdoba: Secretaria de Ciencia y Tecnología de la Universidad Nacional de Córdoba.

Krimsky, S. (1991).The profit of scientific discovery and its normative implications. Chicago Kent Law Review, 75(3), 15-39. Recuperado de https://sites.tufts.edu/sheldonkrimsky/files/2018/05/pub1999TheProfitofScientificDi scovery.pdf

Latour, B. (1983). Give Me a Laboratory and I Will Raise the World. En K. Knorr-Cetina y M. Mulkay (Eds.), Science Observed: Perspectives on the Social Study of Science (pp. 141-170). Londres: Sage. Recuperado de http://www.b runo-latour.fr/sites/default/files/12-GIVE-ME-A-LAB-GB.pdf

Linares, J. (2008). Ética y mundo tecnológico. México D. F.: Fondo de Cultura Económica.

Lundvall, B. A. (1992). National Systems of Innovation. Towards a Theory of Innovation and Interactive Learning. Londres: Pinter.

Manzanal, M. (2012).Poder y desarrollo. Dilemas y desafíos frente a un futuro ¿cada vez más desigual? En M. Manzanal y M. Ponce (Orgs.) La desigualdad ¿del desarrollo? Controversias y disyuntivas del desarrollo rural en el norte argentino (pp. 17-49). Buenos Ares: Ciccus.

Marx, K. (2003 [1867]). El proceso de producción del capital. En El capital (Tomo I, Vol. II, pp. 379-758). Buenos Aires: Siglo XXI.

Motta, R. y Alasino, N. (2013). Medios y política en la Argentina: las disputas interpretativas sobre la soja transgénica y el glifosato. Question, (1)38, 323-335. Recuperado de http://sedici.unlp.edu.ar/handle/10915/29701

Munasqa nació en la EEAOC y cruzó fronteras. (27 de diciembre 2013). La Gaceta. Recuperado de https://www.lag aceta.com.ar/nota/573573/economia/munasqa-nacio-eeaoc-cruzo-fronteras.html

MINCyT. (2016). Obispo Colombres, ejemplo de articulación público-privada. Recuperado de: http://www.mincyt.go b.ar/noticias/obispo-colombres-ejemplo-de-articulacion-publico-privada-12194 
Ministerio de Hacienda y Finanzas Públicas, Secretaría de Política Económica y Planificación del Desarrollo (2016). Informes Productivos Provinciales, Tucumán. Recuperado de: https://www.economia.gob.ar/peconomica/dnpe r/fichas_provinciales/Informe_Productivo_tucuman.pdf

Moyano, R. D., Campi, D. E. A. y Lenis, M. L. (2011). La formación de un complejo científico-experimental en el norte argentino: La estación experimental agrícola de Tucumán (1909-1922). Prohistoria, 16(12), 1-18. Recuperado de http://hdl.handle.net/11336/66976

Natera Rivas, J. J. y Batista Zamora, A. E. (2005). La evolución del sector agrícola en Tucumán (Argentina) desde finales del siglo XIX: una aproximación a través de la dinámica de la evolución de cultivos. Scripta Nova, IX(197). Recuperado de http://www.ub.edu/geocrit/sn/sn-197.htm

Nowotny, H., Scott, P. y Gibbons, M. (2001). Re-Thinking Science. Knowledge and the Public in an Age of Uncertainty. Cambridge: Polity Press.

Oszlak, O. (2015 [1977]). Notas críticas para una teoría de la burocracia estatal. En M. Levi, M. Weber, T. Skocpol, P. Evans y O. Oszlak (Comps.) El valor estratégico de la gestión pública. Trece textospara comprenderla (pp. 289-345). Buenos Aires: Corporación Andina de Fomento.

Palladino, P. (2002). Plants, Patients and the Historian: (Re)membering in the Age of Genetic Engineering. Manchester: Manchester University Press.

Ploper, L. D., Fadda, G. S. y Olea, I.L. (Eds.) (2009). En el mañana hoy. Un recorrido por los 100 años de innovaciones tecnológicas de la EEAOC. Las Talitas: Estación Experimental Agroindustrial Obispo Colombres.

Pestre, D. (2005). Ciencia, dinero y politica. Un ensayo de interpretación. Buenos Aires: Nueva Visión.

Teubal, M. (2001). Globalización y nueva ruralidad en América Latina. En Una nueva ruralidad en América Latina (pp. 45-46). Buenos Aires: CLACSO.

Teubal, M., Domínguez, D. y Sabatino, P. (2005). Transformaciones agrarias en Argentina. Agricultura industrial y sistema agroalimentario. En N. Giarracca y M. Teubal (Coords.). El campo argentino en la encrucijada: estrategias y resistencias sociales, ecos en la ciudad (pp. 37-78). Buenos Aires: Alianza.

Tort, M. I. (1983). Los contratistas de maquinaria agricola: una modalidad de organización económica del trabajo agricola en la pampa húmeda. Buenos Aires: CEIL.

Vara, A. M. (2004). Transgénicos en Argentina: más allá del boom de la soja. Revista Iberoamericana de Ciencia, Tecnologia y Sociedad, 3(1), 101-129. Recuperado de http://www.revistacts.net/files/Volumen\%201\%20-\%20 Número\%203/CTS3.pdf

\section{Notas}

1 El trabajo de campo dentro de la EEAOC fue realizado durante el verano de 2016 junto al Dr. Agustín Piaz, a quien agradezco que me haya permitido disponer libremente de los materiales. La muestra total está integrada por 27 entrevistas a integrantes de la EEAOC que cumplen o cumplieron funciones diversas dentro del esquema de investigación de la institución (becarios/as, investigadores/as y directivos/as). Además del uso gramatical habitual, se emplean comillas para indicar lenguaje nativo aun por fuera de las citas de entrevistas.

2 Se conoce bajo este nombre el proyecto de investigación y desarrollo tecnológico impulsado durante la Segunda Guerra Mundial que culminó en la obtención de las dos bombas nucleares. Liderado por Estados Unidos, con apoyo del Reino Unido y Canadá, es tomado habitualmente como un hito de Big Science, que implicó la consolidación de la ciencia y la tecnología como cuestiones de Estado (Dickson, 1988). Es también un hito en relación con la percepción social de los desarrollos científicos y tecnológicos, que durante la segunda mitad del siglo XX cuestionará reiteradamente su carácter benefactor (Pestre, 2005).

3 A partir del lanzamiento de las bombas nucleares y luego durante la década de 1960, de la mano de movimientos ambientalistas y la conformación de los partidos verdes en Europa, se advierten fuertes cuestionamientos al desarrollo científico-tecnológico. Dickson (1988) también señala que, a la reacción social y académica, se suma una gubernamental que busca encauzar estas reacciones, por ejemplo a partir de la creación de la Oficina de Protección Ambiental (EPA) en Estados Unidos.

4 Para un análisis de los primeros procesos de institucionalización de las ciencias agropecuarias y el rol desempeñado por el Estado y el sector privado, véase Graciano (1998; 2017). Para el caso tucumano, véase Moyano, Campi y Lenis (2011). 
Cecilia Gárgano. Estado y ciencia empresarial en la Argentina del agronegocio. Implicancias políti...

5 De junio de 1958 a mayo de 1959 como interventor fue designado Juan Carlos Ledesma. Poco después, un nuevo decreto dictaminó el fin de la intervención.

6 Encabezados por Everett Rogers, estos enfoques sientan las bases para la orientación de la extensión rural y la investigación en el marco de la revolución verde (Alemany y Sevilla Guzmán, 2007, p. 56).

7 Si bien durante la década de 1960 la producción agrícola pampeana recuperó el nivel alcanzado en las décadas de 1920 y 1930, en torno a los 16.000.000 de toneladas, fue en estos años cuando se llegó a los 36.000.000 de toneladas de cereales y oleaginosas en la región pampeana y a los 44.000 .000 de toneladas en todo el país (Balsa, 2006).

8 Desde la academia una de las primeras voces críticas fue la de Andrés Carrasco, quien antes de publicar los resultados de sus investigaciones (sobre efectos nocivos de exposición al glifosato asociados a malformaciones de embriones anfibios y pollos) en reconocidas revistas internacionales lo hizo, en abril de 2009, en el diario Página 12, consciente de la necesidad y responsabilidad de darlos a conocer en forma masiva y urgente. Esta posición y la denuncia sostenida le valieron la persecución del conjunto del establishment académico y político nacional; véase (Blois, 2016, Arancibia, 2013, entre otros). Dentro de los movimientos sociales, fueron pioneras las Madres de Ituzaingó, barrio cordobés del mismo nombre afectado por las fumigaciones. También el Grupo de Reflexión Rural (GRR) cumplió un rol pionero en la realización de campañas contra las fumigaciones con agrotóxicos y relevamientos. Para una reconstrucción del rol de los medios de comunicación en torno a la dicotomía inocuo/nocivo, véase Motta y Alasino (2013). Los trabajos de Vara, en especial Vara (2004), analizan la producción científica en este terreno problematizando su condición periférica.

9 La Gaceta, "La Obispo Colombres cumple 110 años junto a la agroindustria", 27 de julio de 2019. Recuperado de http s://www.lagaceta.com.ar/nota/813470/actualidad/obispo-colombres-cumple-110-anos-junto-agroindustria.html

10 Barañao, L. (2012). La nación difundirá el modelo de la EEAOC a toda la Argentina. La Gaceta, (28 de julio 2012), p. 15. Recuperado de https://www.lagaceta.com.ar/nota/502931/economia/nacion-difundira-modelo-eeaoc-toda-arg entina.html

11 EEAOC (s/f), Recuperado de http://www.eeaoc.org.ar/noticias/193/Celebracion-del-103-Aniversario.html

\section{BY-NC-SA}

